\title{
Analysis of hydrobiological pattern in the Bizerte lagoon (Tunisia)
}

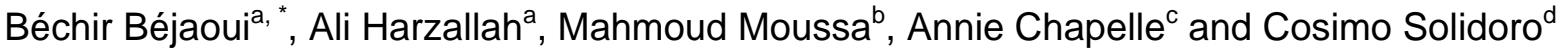 \\ a Laboratoire Milieu Marin, Institut National des Sciences et Technologies de la Mer, 28, rue du 2 mars 1934 , \\ 2025 Salammbô, Tunisia \\ ${ }^{\mathrm{b}}$ Laboratoire d'Hydraulique, Ecole Nationale d'Ingénieurs de Tunis, BP 37 Le Belvédère, 1002 Tunis, Tunisia \\ c Département IFREMER DEL/EC Brest, BP 70, 29280 Plouzané, France \\ d Istituto Nazionale di Oceanografia e di Geofisica Sperimentale, OGS Borgo Grotta Gigante 42/C, 34010, \\ Sgonico, Trieste, Italy
}

*: Corresponding author : Béchir Béjaoui, email address : $\underline{\text { bejaoui.bechir@instm.rnrt.tn }}$

\begin{abstract}
:
This study deals with the use of a multivariate analysis method in order to understand the functioning of the Bizerte lagoon ecosystem. A set of hydrobiological parameters was collected during 10 monthly campaigns in 2004. A variant of the EOF (Empirical Orthogonal Function) technique is used to examine hydrobiological variability modes in this lagoon. The permanent features characterising the lagoon are obtained by applying the EOF technique to data after removing the annual cycle. Two major modes were obtained. The first one shows a contrast between the northern sector of the lagoon, influenced by the Mediterranean Sea, and the southern one influenced by continental waters. This mode is mostly prominent for temperature and salinity. The second mode shows a contrast between shallow waters along the coastal zones and the deep central area of the lagoon. This contrast is more pronounced towards the southwestern edge of the lagoon, a region of important freshwater input from the Tinja channel, which drifts towards the downstream area of Menzel Bourguiba. This second mode may also correspond to northward water circulation under southerly wind blowing frequently in summer. The spatial and temporal variability in the lagoon is highlighted by applying the EOF to the raw data without removing the annual cycle. A weight series is obtained for each variable by extracting the corresponding data and then projecting them on the corresponding eigenvector. Using this technique, only one mode was found dominant with more than $52 \%$ of the total variance. It was also found that the north-south contrast of temperature, salinity and phosphorous and the coast-centre contrast of Chlorophyll a are enhanced in summer. Other variables such as ammonia and nitrate also show significant annual cycles but with local patterns.
\end{abstract}

Keywords: Bizerte lagoon; EOF analysis; nutrient cycles 


\section{Introduction}

Many lagoons in the Mediterranean basin suffer from degraded conditions, because of the anthropogenic pressures, including urban, agricultural and industrial waste (De Casabianca et al., 1997; Solidoro et al., 2005). The risk of eutrophication increases correspondingly, even though the exchange with marine waters, which usually are more oligotrophic, is a mitigation factor (Pitta et al., 2001; Ridame and Guieu, 2002). Given the high value of lagoon ecosystems, in terms of biodiversity and socio-economic facilities, it is important to continue to reinforce actions aiming to protect and restore these ecosystems. This requires a proper knowledge of the basic ecosystem functioning (IFREMER, 2000).

The Empirical Orthogonal Functions (EOF) analysis is a numerical technique widely used in the study of ocean and atmospheric datasets (Kutzbach, 1967; White et al., 1958; Loève, 1963; Schrum et al., 2006). The EOF technique aims to reduce the dimensionality of a dataset by projecting the samples on to a smaller dimension space spanned by a number of orthogonal axes, chosen so as to retain most of the information (Escofier and Pagès, 1990). It also allows to optimize the appropriate choice of parameters, the spatial distribution and the sampling frequency of monitoring programs (Ben Hamadou et al., 2001). The method is formally analogous to the Principal Component Analysis, and was first developed by Pearson (1901) and Hotelling (1933). The method was also applied to hydrobiological data (Ibanez, 1976; Engtrom-Ost et al., 2002 ; Duigan and Kovach, 1991; Legendre and Legendre, 1998 ; Carrel et al., 1986 ; Larissi et al., 2001). The study of Labbardi et al. (2005) brought out the physico-chemical characteristics of Moulay Bousselham lagoon (Morocco) using the EOF technique.

The aim of this study is to investigate the hydrobiological functioning of the Bizerte lagoon using the EOF decomposition with two different normalization procedures. We shall demonstrate that those approaches are efficient for the derivation of patterns describing the functioning of this ecosystem. In section 2 we will present the laboratory analyses and the EOF approach. In section 3, the results concerning permanent and variable features derived from the EOF decomposition will be commented on. The paper ends with a discussion in section 4.

\section{Material and methods}

\subsection{Study site}

The Bizerte lagoon is a Mediterranean lagoon located in the northern coast of Tunisia (latitude: $37^{\circ} 8^{\prime}-$ $37^{\circ} 14^{\prime} \mathrm{N}$, longitude: $9^{\circ} 46^{\prime}-9^{\circ} 56^{\prime} \mathrm{E}$ ). It covers an area of $128 \mathrm{~km}^{2}$ and has a mean depth of $7 \mathrm{~m}$. It is connected to the Mediterranean Sea through a 6-km long inlet and to the Ichkeul Lake through the Tinja channel, which is approximately 5-km long and a few meters in depth $(3 \mathrm{~m}$ in the overflow period) (Fig. 1). The lagoon lies in the vicinity of several towns (Bizerte, Zarzouna, Menzel Abderrahmen, Menzel Jemil, and Menzel Bourguiba) and industrial units (Fig. 2). This ecosystem is affected by various anthropogenic activities, including domestic sewage input, industrial waste, atmospheric pollution, farmland and bivalve aquaculture.

Water temperature in the lagoon follows a seasonal cycle, ranging between $10^{\circ} \mathrm{C}$ in winter and $28^{\circ} \mathrm{C}$ in summer (Harzallah, 2002). The water salinity ranges from 30 in winter to 38 in summer (ANPE, 1990, Béjaoui et al., 2005). As far as we know, no detailed current observations in the lagoon have been made. Only a schematic circulation based on a visual depiction was mentioned by Frisoni et al. (1986). They showed a cyclonic circulation with convergence towards the lagoon centre. A recent study, based on numerical modelling, was performed by Harzallah and Koutitonsky (2001) focusing on water and heat exchange between the lagoon and the Mediterranean Sea.

The evaporation in the lagoon is great (166 Million $\mathrm{m}^{3} / \mathrm{year}$ ) particularly in summer (166 Million $\mathrm{m}^{3} /$ year). Precipitation does not exceed 146 Million $\mathrm{m}^{3} / \mathrm{year}$ in winter and it is weak and scarce in summer (74 Million $\left.\mathrm{m}^{3} / y e a r\right)$. The water input from the Ichkeul Lake has dramatically decreased during the last decades as an effect of the construction of dams discharging into this Lake (MAERH, 2003). This has led to significant alteration of the water characteristics of the lagoon, particularly a dramatic increase in salinity. 


\subsection{Experimental observation}

Ten sampling campaigns were carried out during the year 2004, from January to December, roughly monthly. In situ measurements and water sampling were performed during those campaigns. Eight out of the 10 campaigns (January, February, March, April, July, August, November, and December) covered 10 sampling stations (Fig. 2). Two campaigns had a finer spatial resolution, with 118 sampling stations in May and 40 sampling stations in September.

In-situ measurements concerned temperature $(\mathrm{T})$, salinity $(\mathrm{S})$, dissolved oxygen $\left(\mathrm{O}_{2}\right)$ and transparency (Tr). Water temperature was measured at approximately $10 \mathrm{~cm}$ below the surface with an electronic thermometer. Salinity and dissolved oxygen content were measured using, respectively, a microprocessor conductimeter (Orion 115Aplus) and an Oxymeter (Orion 810Aplus) calibrated beforehand. The vertical mitigation coefficient for the downward irradiance was measured with a Secchi disc (Holmes, 1970).

The laboratory analyses of the surface water samples were performed for the parameters mentioned below. The analyses of ammonia $\left(\mathrm{NH}_{4}\right)$, nitrates $\left(\mathrm{NO}_{3}\right)$, nitrites $\left(\mathrm{NO}_{2}\right)$ and phosphorous $\left(\mathrm{PO}_{4}\right)$ were carried out using an Auto-analyser (Treguer and Le Corre, 1975). The total nitrogen (N-NT) and total phosphorus (P-PT) were determined after mineralization, respectively, into ammonia and orthophosphate (Rodier et al., 1996). The suspended matter (SM) concentration is measured after filtration through Whatman membrane filters (pore size: $0.45 \mu \mathrm{m})$. The Chlorophyll a $(\mathrm{Chl}$ a) and Pheopigment (Pheo) contents were determined using the spectrophotometric method of Lorenzen (1967) and following the procedure given by Parsons et al. (1984) after $24 \mathrm{~h}$ extractions in 90\% acetone at $-5^{\circ} \mathrm{C}$ in the dark.

\subsection{Data analysis}

The data collected in different months were firstly interpolated with reference to a common grid covering the total lagoon area, by using a bilinear interpolation and distances as weights. A $1783 \mathrm{x}$ 111 matrix was then constructed using the interpolated data $(x b)$. Each column represents the spatial distribution (1783 grid points) of one variable for one campaign, here referred to as parameter (111 parameters) and each row represents the seasonal evolution of each variable in one mesh grid-point, here referred to as station (1783 stations). During some campaigns, a few parameters were missing.

Two EOF decomposition approaches were applied using different standardizing procedures. In the first approach, the space average over the total area of the lagoon was removed from each parameter, in order to filter out the seasonal cycle. The data were then normalized by the spatial standard deviation. The resulting data matrix representing anomalies is given as follows:

$$
x s_{i j}=\frac{x b_{i j}-\overline{x b}_{j}}{s b_{j}}
$$

where $i$ refers to the $i^{\text {th }}$ station and $j$ to the $j^{\text {th }}$ parameter; $\overline{x b}_{j}$ is the spatial mean of the $j^{\text {th }}$ parameter and $s b_{j}$ its spatial standard deviation. The correlation matrix $C s_{j j^{\prime}}(111 \times 111)$ is then constructed from the matrix $x s$. Eigenvalues $\lambda s_{k}$ and eigenvectors $v s_{j k}$ of this symmetric matrix are computed. The subscript $k$ refers to the $k^{\text {th }}$ mode corresponding to the $k^{\text {th }}$ eigenvalue and the $k^{\text {th }}$ eigenvector. The projection of the data matrix $x s$ on the eigenvectors vs gives the loadings $y s$.

$$
y s_{k i}=\sum_{j} x s_{i j} * v s_{j k}
$$

This first approach is used in order to emphasize the common spatial features for the whole observed period. We termed the results from this analysis "permanent modes". 
In the second approach, the time average of each variable is removed. The data are then normalized by the temporal standard deviation. The resulting matrix $x t$ is given as follows:

$$
x t_{i j}=\frac{x b_{i j}-\overline{x b}_{i}}{s b_{i}}
$$

with $x t_{i j}$ is an element of this matrix, $\overline{x b}$ is the time average and $s b_{i}$ is the temporal standard deviation of each variable in the $i^{\text {th }}$ station. The correlation matrix $C t_{j j^{\prime}}(111 \times 111)$ is then constructed from the matrix $x t$. Eigenvalues $\lambda t_{k}$ and eigenvectors $v t_{j k}$ of this symmetric matrix are calculated in the same way as in the first approach.

In order to obtain the contribution of each variable $p$ to the variability modes we construct a submatrix $x p$ from $x t$ retaining only the elements related to the variable considered. For example, the submatrix of temperature is obtained by retaining from the 111 parameters only those relative to temperature (its dimension is $1738 \times 10$ relative to 10 monthly campaigns). This submatrix $x p$ is then projected on a submatrix $v p$ obtained from matrix $v t$ by the retention of elements relative to the variable $p$. The resulting loadings matrix $y p$ is given as follows:

$$
y p_{k i}=\sum_{j} x p_{i j} * v p_{j k}
$$

Therefore, seasonal evolution and spatial weights relative to each variable are extracted from a single EOF decomposition common to the whole dataset. This second approach enables us to investigate the space-time variability in the lagoon including the seasonal cycle. We termed the results from this analysis "variable modes".

The method followed here presents some similarities with the Extended Empirical Orthogonal Functions (EEOF) technique (Weare and Nasstrom, 1982) and the Singular Spectral Analysis (SSA) method (Vautard and Gill, 1989) where the matrix is extended with the same variables lagged in time. Other methods such as Singular Value Decomposition (SVD) and Canonical Correlation Analysis (CCA) (Bretherton et al., 1992; Wallace et al., 1992) permit the obtention of the associated spatial patterns for two or more variables. In these methods, each mode has one time series common to all variables. In our approach, the eigendecomposition provides a separate time series for each variable, but starting from a single, common, EOF on all data set.

\section{Results}

\subsection{Hydrobiological data}

The spatial range (minimum and maximum) of the physico-chemical and biological parameters recorded during the sampling period is summarized in Tables 1 and 2. Water temperature and salinity vary, respectively, from 11.5 to $29.5^{\circ} \mathrm{C}$ and from 32.0 to 36.8. Dissolved oxygen content exhibits an obvious seasonal variation from $3.1 \mathrm{mg} \mathrm{I}^{-1}$ in summer to $10 \mathrm{mg} \mathrm{I}^{-1}$ in winter. The concentration of suspended matter varies from $7.0 \mathrm{mg} \mathrm{l}^{-1}$ in summer to $38.5 \mathrm{mg} \mathrm{l}^{-1}$ in winter. The water transparency ranges between 0.6 and $6.0 \mathrm{~m}$. Clear waters are observed in the lagoon centre in May.

The ammonia content exhibits a large seasonal variability $(0.02 \mu \mathrm{M}$ in May - $3.4 \mu \mathrm{M}$ in July). The high nitrogen anions content $\left(\mathrm{NO}_{3}+\mathrm{NO}_{2}\right)$, measured during the sampling period is about $5.2 \mu \mathrm{M}$. The maximum phosphorous content is about $0.6 \mu \mathrm{M}$ in summer. The contents of total nitrogen and total phosphorus vary seasonally respectively from 6.5 to $17.5 \mu \mathrm{M}$ and from 0.5 to $2.8 \mu \mathrm{M}$, and that of $\mathrm{Chl} a$ ranges between $2.1 \mathrm{mg} \mathrm{I}^{-1}$ in March and $9.6 \mathrm{\mu g} \mathrm{I}^{-1}$ in August. We note that the nutrients and Chl $\mathrm{a}$ 
concentrations recorded during the sampling period are lower than those observed before the connection of the urban and industrial waste to the ONAS-network (National Sanitation Utility) (MAERH, 2003).

\subsection{Permanent features}

The first two modes resulting from the eigendecomposition accounted for $26 \%$ and $18 \%$ of the total variance, respectively. The third mode explained only $13.6 \%$. Therefore, only the results for the two leading modes are considered. The loadings of these first two modes are presented in Fig. 3 and 4, respectively. The contribution of each parameter to the permanent features modes can be assessed by its weight. Table 3 reports these weights. Parameters with a mean weight not significantly different from zero (t-test to check the null-hypothesis of the mean with $5 \%$ probability error) are marked by the minus sign (-).

The leading mode shows a clear north-south gradient (Fig. 3). The lagoon is divided mainly into two sectors. The northern sector extends from the Mediterranean Sea through the inlet towards the centre of the lagoon. The southern sector covers the southern coastal zones and the southwestern areas close to the Tinja channel mouth, where the highest loadings are observed. This mode clearly reflects the opposition between areas under the effect of the Mediterranean Sea and those affected by the Ichkeul Lake and the other rivers.

The variables showing mean weights different from zero are $\mathrm{T}, \mathrm{S}, \mathrm{Tr}$, and $\mathrm{Tr} \%$. Conversely, the chemical and biological parameters do not contribute to this standing mode. The variables $\mathrm{S}$ and $\mathrm{Tr}$ have positive weights whereas $\mathrm{T}$ and $\mathrm{Tr} \%$ have negative ones. Therefore, the dark area in figure 3 (high negative loadings) reflects low salinity and transparency and relatively high temperature. The former variables ( $\mathrm{S}$ and $\mathrm{Tr}$ ) correspond to freshwaters loaded with suspended matters coming from the tributaries (Ichkeul Lake and rivers). The latter one $(T)$ corresponds to shallow regions. On the contrary, the centre and the northwest sector of the lagoon show high salinity and transparency and cooler waters, reflecting the influence of marine waters. The relative transparency, which is high in the south and low in the central and northwestern sectors of the lagoon may be attributed to the effect of topography.

The loadings associated with the second mode highlight an east-west contrast (Fig. 4). They also reflect the local effect of the Tinja channel in the western side of the lagoon and the area close to the industrial zone of Menzel Bourguiba. The loadings in these two contrasting regions have opposite signs, however, those close to the Tinja channel mouth are much higher. The weights (Table 3 ) show that not only $\mathrm{Tr}$, Tr\% but also $\mathrm{Chl}$ a and Pheo have mean values significantly different from zero. Close to the Tinja channel mouth, transparency is weak and Tr\% is high. This again reflects the effect of water input from the Ichkeul Lake. In this region (Tinja channel mouth) the Pheo content is low whereas that of $\mathrm{Chl} a$ is much higher. It is suggested that the phytoplankton originating from Ichkeul Lake is transported southeastward by the currents. When it reaches the area in front of the industrial zone of Menzel Bourguiba, phytoplankton encounters unfavourable conditions (Sakka Hlaili et al., 2008) and then is transformed into Pheo. This explains the high Pheo content, low Chl a content and high transparency. This situation may correspond to the dominant northwestern wind. When the wind is southeast, which is frequent in summer, the phytoplankton close to the Tinja channel mouth and pheopigment in front of Menzel Bourguiba drift northwards, consistent with the spatial distribution of this mode (mean gradient in Fig. 4).

\subsection{Variable features}

The first two modes of the eigendecompostion for variable features accounted for $52 \%$ and $12 \%$ of the total variance. Hence, in this case, only the first mode is retained. To assess the contribution of each parameter to this mode, the spatial mean of squared weights was considered (Table 4). The variables which contributed most to this mode were $\mathrm{T}$, $\mathrm{S}$, and - to a lesser extent - $\mathrm{O} 2, \mathrm{NH}_{4}, \mathrm{NO}_{3}, \mathrm{PO}_{4}$, and $\mathrm{Chl}$ a. The loadings and weight series for these parameters are shown in Fig. 5.

\subsection{Physical parameters}

The loadings and weight series for temperature (Fig. 5A) and salinity (Fig. 5B) are quite similar. Both of them show a north-south contrast with high variability in the southern sector and low in the inlet due to the influence of the sea. The weight series shows a clear annual cycle reaching its maximum in late summer and minimum in late winter. 
Both weight series of temperature and salinity indicate that the spatial contrast, mentioned in Section 3.2 , is more prominent in summer and winter, and less during the intermediate seasons. In late summer the hot and dry conditions increase the water temperature and the salinity in the southern lagoon sector, because of evaporation. In late winter cold and wet conditions lead to the opposite situation. These variations are attenuated in the northern sector due to the continuous water exchange with the Mediterranean Sea through the inlet. The spatial distribution also evidences some differences with that of the leading mode of the permanent features (Fig. 3) concerning temperature and salinity. In particular, the salinity and temperature loading maps indicate that high values are observed in the southeastern sector close to the river mouths.

\subsection{Chemical and biological parameters}

The loadings and weight series of the chemical and biological parameters which contribute significantly (according to our criterion) to the first leading mode of variable features are presented in Fig. 5 C to $5 G$.

Despite missing data, the oxygen weight series clearly shows a seasonal signal, positive in summer and negative in winter (Fig. 5C). This high seasonal variability is related essentially to meteorological conditions. The maximum is observed in the northeastern zone of the lagoon, an area known for its low oxygen content in summer (negative weights), due to the low dynamism and shellfish activity (Brahim, 1994; Dellali, 1996). On the other hand, the southwestern sector is under the influence of Tinja channel and of the inlet, which are characterized by a weak seasonal variability of oxygen content.

The Chl a loadings map (Fig. 5D) suggests an important seasonal variability in the costal areas and in the inlet. This seasonal variability is linked to the effect of the terrestrial discharge and seawaters. A weak $\mathrm{Chl}$ a seasonal cycle is found in the lagoon centre stretching towards the harbour of Menzel Bourguiba. As mentioned above, the latter region is known as an area of industrial waste which probably inhibits phytoplankton growth. The $\mathrm{Chl}$ a weight series shows the largest values in spring and summer reaching a maximum in late summer at the moment of phytoplankton growth (Harzallah, 2002). Observations made in the lagoon indicated no clear bloom in the area close to the harbour of Menzel Bourguiba. Chl a levels recorded in summer in this area by Sakka Hlaili et al. (2007) were significantly lower (1.9-2.9 $\left.\mathrm{g} \mathrm{l}^{-1}\right)$ than those measured in other areas inside the lagoon.

The ammonia loadings map (Fig. 5E) allows us to distinguish two regions with a large seasonal variability, the northeastern sector and the region close to Menzel Bourguiba harbour. The weight series indicates a low ammonia content in spring followed by an increase in summer. The lower variability, observed in the south sector can be explained by the continuous urban discharge.

The nitrate loadings map (Fig. 5F) is quite similar to that of ammonia except the high nitrate loadings in the inlet. Hence the regions characterized by a high seasonal variability for nitrate content are the same as those for ammonia. However, to a large extent, the nitrate time series is opposite to that of ammonia. In summer, low nitrate content coincides with a high ammonia content whereas in winter the situation is reversed. The low oxygen content in summer could explain this opposite variation.

The phosphorous loadings map (Fig. 5G) shows positive loadings in the southern sector and slightly negative loadings in the northern sector. Hence, to some extent this mode represents a north-south oscillation. The weight series shows an annual cycle with a maximum contribution in summer and minimum one in winter. The phosphorous content in the southern sector increases in summer and decreases in winter whereas it exhibits the opposite variations but moderately in the north. The low seasonal variability in the northern lagoon is attributed to the Mediterranean Sea effects. The rapid decrease of the phosphorous content in early autumn could be related to the phytoplankton bloom during this period.

\section{Discussions}

In this study, we analysed the space and time variability of major biogeochemical properties in the Bizerte lagoon, by using a numerical procedure based on the EOF decomposition technique and experimental observations. The purpose of the analysis was to decouple space and time variability of the dataset in a number of spatial maps (loadings) and associated monthly weight series. In this way it was possible to elucidate major spatial features and temporal variations of the ecosystem. Considering simultaneously the co-evolution of different parameters it was possible to disentangle and rank the contribution of each one to the total variability of the system. The projection of the resulting 
subeigenvector on the parameter subset gives its proper loadings. This enables us to speculate on possible sources of variability for different parameters and on the basic functioning of the ecosystem. A standard monovariate EOF analysis, applied separately to each parameter (not shown), reveals different results compared to the approach applied in this paper, for example in the $\mathrm{Chl}$ a structure.

The application of the method revealed two permanent features reflecting the typical functioning of the lagoon. The first one reflects a north-south contrast. The factors causing this contrast are related essentially to the influence of the catchment area and the marine waters. Indeed, the southern sector is under the influence of the rivers' input that drain the southern catchment area. It is also under the influence of freshwater input of the Tinja channel, which drifts southeastward according to the hydrodynamic circulation (Frisoni et al., 1986). In contrast, the northern sector - which does not have significant rivers - is largely influenced by sea waters. These differences maintain the north-south contrast. The studies carried out by Sakka Hlaili et al. $(2007,2008)$, which distinguish two different trophic chains in the northern and southern sectors of the Bizerte lagoon, corroborate the subdivision of the lagoon into two sectors.

The second mode of the permanent features indicates a contrast between the lagoon coastal zones, especially the area close to the Tinja channel mouth and the central part of the lagoon extending towards the Menzel Bourguiba area (southwest of the lagoon). It is hypothesized that this pattern represents the contrast between the shallow waters characterized by high turbidity and $\mathrm{Chl}$ a content and the deep waters where pheopigment is predominant. The extension towards the Menzel Bourguiba area results from a combination of water circulation and environmental conditions. Indeed, the phytoplankton coming from the Ichkeul Lake drifts southeastward with the currents. It encounters unfavourable conditions in front of the Menzel Bourguiba harbour where it could be transformed into pheopigment. The circulation scheme provided by Frisoni et al. (1986) showing a dominant counter clockwise circulation - mainly forced by wind with negligible effect of tide (Mansouri, 1996) - and the study of Sakka Hlaili et al. (2008) support the hypothesis.

Northward circulation conditions that prevail under southerly wind, which is frequent in summer, may also contribute to this second mode. In this case phytoplankton and pheopigment are drift northward consistent with the mean gradient shown in Fig. 4. Additional current measurements and numerical modelling are needed to further confirm it.

For the variable features one major mode was obtained. The loadings of this mode have some similarities with those of the permanent features. Indeed this mode corresponds to amplification or attenuation of the permanent features according to season. The north-south contrast of temperature and salinity is more noticeable in summer than in winter. This contrast also involves phosphorous with enhancement in summer. The rise in phosphorous content in summer is likely linked to an increase in phosphorous release from the sediment porewaters, caused by water warming. We have also found a summer enhancement of the second mode of permanent features of $\mathrm{Chl}$ a.

Besides these annual cycles, some particular features have been depicted for a few parameters. We note in particular, a large seasonal variability of $\mathrm{NH}_{4}$ and $\mathrm{NO}_{3}$ contents close to the Menzel Bourguiba harbour and $\mathrm{O}_{2}$ content in the northeastern sector. The latter sector is characterized by shallow water, which is sensitive to seasonal variations and eutrophication; whereas the area of Menzel Bourguiba is affected by the metallurgical wastes of the El Fouledh factory.

The current approach applied to the Bizerte lagoon allows us to obtain a precise view of its hydrobiological pattern, retaining only the parameters which significantly contribute to it. In addition, concerning the variable features, each variable has its own time series. In the regular EOF analysis, one time series is obtained for all variables.

On the basis of this study, we can conclude that the biogeochemical functioning of the lagoon is essentially controlled by three entities, the Mediterranean Sea, the Ichkeul Lake and the catchment area, particularly the Menzel Bourguiba industrial zone. Any human intervention on the level of these latter entities (construction of dams, break-waves and industrial waste) may modify the distribution of biogeochemical properties of this ecosystem and consequently modify the biotope. We have also found that the north-south and east-west contrasts are mostly prominent for temperature, salinity, transparency, $\mathrm{Chl} a$ and pheopigment. These variables therefore are of particular importance for hydrobiological study in this area. It is likely that these two contrasts were more noticeable before the construction of dams on the principal rivers pouring into the Ichkeul Lake and the Bizerte lagoon.

In future research work it would be important to take into account the dynamical aspects such as the water circulation. 


\section{Acknowledgments}

This study was carried out within the framework of the Tunisia National Research Project EL BIHERA for the period from 2002 to 2006.

\section{References}

ANPE, 1990. Etude préliminaire de l'écologie du lac de Bizerte. Rapport, Agence Nationale de Protection de l'Environnement, Tunis, $100 \mathrm{pp}$.

Ben Hamadou, R., Ibanez, F., Souissi, S., Cathelineau, A.C., 2001. Spatial analysis of hydrogical and phytoplanktonic data of Bay of Tunis, Multivariate cartography. Mediterranean Marine Science 2, 6785.

Béjaoui, B., Ben Charrada, R., Moussa, M., Ben Hamadou, R., Harzallah, A., Chapelle, A., 2005. Caractérisation hivernale de la lagune de Bizerte. Bulletin de l'Institut National des

Sciences et Technologie de la Mer, Salammbô 32, 79-91.

Brahim, M., 1994. Paramètres hydrobiologiques dans le golfe de Tunis et dans la lagune de Bizerte. Rapport, Institut National des Sciences et Technologies de la Mer, Salammbô, 20 pp.

Bretherton, C.S., Smith, C., Wallace, J.M., 1992. An intercomparison of methods for finding coupled patterns in climate data. Journal of Climate 5, 541-560.

Carrel, G., Barthélémy, D., Auda, Y., Chessel, D., 1986. Approche graphique de l'analyse en composantes principales normée : utilisation en hydrobiologie. Acta Ecologica, Ecologia Generalis 7, 189-203.

De Casabianca, M.L., Laugier, T., Marinho-Soriana, E., 1997. Seasonal changes of nutrients in water and sediment in a Mediterranean lagoon with shellfish farming activity (Thau lagoon, France). Journal of Marine Science 54, 905-916.

Dellali, M., 1996. Etat de la pollution de la lagune de Bizerte et effets à court terme de certains polluants sur Spheroma serratum (Fabricius, 1987) Idotea balthica (Pallas, 1772) et Ruditapes decussatus (Linne, 1758), Rapport, DEA. Faculté des Sciences de Tunis, 143 pp.

Duigan, C.A., Kovach, W.L., 1991. A study of the distribution and ecology of littoral freshwater Chydorid (Crustacea, Cladocera) communities in Ireland using multivariate analyses. Journal of Biogeography 18, 267-280.

Engtrom-Ost, J., Koski, M., Schmidt, K., Viitasalo, M., Jonasdottir, S.H., Kokkonen, M., Repka, S., Sivonen, K., 2002. Effects of toxic cyanobacteria on a plankton assemblage : community development during decay of Nodularia spumigena. Marine Ecology Progress Series 232, 1-14.

Escofier, B., Pagès, J., 1990. Analyses factorielles simples et multiples. Objectifs, méthodes et interprétation. Dunod, Paris, $287 \mathrm{pp}$.

Frisoni, G.F., Guelorget, O., Perthuisot, J.P., 1986. Evaluation des potentialités aquacoles du lac de Bizerte. Rapport, Institut National des Sciences et Technologie de la Mer, Salammbô 44 pp.

Harzallah, A., 2002. Etat actuel et évolution de l'exploitation halieutique et aquacole des lagunes - cas de la lagune de Bizerte. Rapport, Institut National des Sciences et Technologie de la Mer, Salammbô, $128 \mathrm{pp}$.

Harzallah, A., Koutitonsky, V.G., 2001. Observations and numerical simulations of Hydrodynamics of the Bizerte lagoon. Proceedings of the $5^{\text {th }}$ international conference on the Mediterranean Coastal Environment. MEDCOAST 01, Hammamet, pp. 1101-1110.

Holmes, R.W., 1970. The secchi disk in turbid coastal water. Limnology and Oceanography 15, 688694.

Hotelling, H., 1933. Analysis of a complex of statistical variables into principal components.

Journal of Educational Psychology 24, 498-520.

Ibanèz, F., 1976. Contribution à l'analyse mathématique des évènements en écologie planctonique. Optimisation méthodologique; étude expérimentale en continu à petite échelle de l'hétérogénéité du plancton côtier. Bulletin de l'Institut Océanographique, Monaco, 96 pp.

IFREMER, 2000. Mise à jour d'indicateurs du niveau d'eutrophisation des milieux lagunaires méditerranéens. Sète, $412 \mathrm{pp}$.

Kutzbach, J.E., 1967. Empirical Eigenvectors of Sea-Level Pressure, Surface Temperature and Precipitation Complexes over North America. Journal of Applied Meteorology 6, 791-802.

Labbardi, H., Ettahiri, O., Lazar, S., Massik, Z., El Antri, S., 2005. Étude de la variation spatiotemporelle des paramètres physico-chimiques caractérisant la qualité des eaux d'une lagune côtière 
et ses zonations écologiques : cas de Moulay Bousselham, Maroc. Comptes Rendus Geoscience 337, 505-514.

Larissi, J., Ettahiri, O., Hilmi, K., Zizah, S., Makaoui, A., 2001. Variability of hydrological parameters of the Moroccan South Atlantic zone (Boujdor - cape Blanc cape). Proceedings of the 5th international conference on the Mediterranean Coastal Environment. MEDCOAST 01, Hammamet, pp. 1083-1088.

Legendre, P., Legendre, L., 1998. Numerical ecology. Elsevier, Amsterdam, 385 pp.

Loève, M., 1963. Probability Theory. Van Nostrand, New York, 685 pp.

Lorenzen, C. J., 1967. Determination of chlorophyll and pheopigments by spectrophotometric equations. Limnology and Oceanography 12, 34-346.

MAERH, 2003. Etude sur la dépollution industrielle dans le bassin versant du lac de Bizerte. Rapport, Ministère de l'Agriculture, de l'Environnement et des Ressources Hydrauliques, Tunis, 182 pp.

Mansouri, T., 1996. Application de la télédétection et des systèmes d'information géographique a l'étude du fonctionnement hydrologique du lac de Bizerte et son bassin versant. Rapport, DEA. Faculté des Sciences de Tunis, $101 \mathrm{pp}$.

Ridame, C., Guieu, C., 2002. Saharan input of phosphate to the oligotrophic water of the open western Mediterranean sea. Limnology and Oceanography 3, 856-869.

Rodier, J., Bazin, C., Broutin, J.P., Chambon, P., Champsaur, H., Rodi, L., 1996. L'analyse de l'eau. Eaux naturelles, eaux résiduaires, eau de mer. Dunod, Paris, 1383 pp.

Sakka Hlaili, A., Grami, B., Hadj Mabrouk, H., Gosselin, M., Hamel, D., 2007. Phytoplankton growth and microzooplankton grazing rates in a restricted Mediterranean lagoon (Bizerte lagoon, Tunisia). Marine Biology 151, 767-783.

Sakka Hlaili, A., El Grami, B., Niquil, N., Gosselin, M., Hamel, D., Troussellier, M., Hadj Mabrouk, H., 2008. The planktonic food web of the Bizerte lagoon (southwestern Mediterranean) during summer: I. Spatial distribution under different anthropogenic pressures Estuarine, Coastal and Shelf Science 78, 61-77.

Schrum, C., St. John, M., Alekseeva I., 2006. ECOSMO, a coupled ecosystem model of the North Sea and Baltic Sea: Part II. Spatial-seasonal characteristics in the North Sea as revealed by EOF analysis. Journal of Marine Systems 61, 100-113.

Solidoro, C., Pastres, R., Cossarini, G., 2005. Nitrogen and plankton dynamics in the lagoon of Venice. Ecological Modelling 184, 103-124.

Treguer, P., Le Corre, P., 1975. Manuel d'analyse des sels nutritifs dans l'eau de mer. Laboratoire d'océanologie chimique, Bretagne, 5109 pp.

Parsons, T.R., Maita, Y., Lalli, C.M., 1984. A manual of chemical and biological methods for seawater analysis. Pergamon, Oxford sized algae and natural seston size fractions. Marine Ecology Progress Series 199, 43-53.

Pearson, K., 1901. On lines and planes of closest fit to systems of points in space.

Philosophical Magazine 6, 599-572.

Pitta, P., Gionnakourou, A., Christaki, U., 2001. Planktonic ciliates in the oligotrophic Mediterranean sea: longitudinal trends of standing stocks, distributions and analysis of food vacuole contents. Aquatic Microbial Ecology 24, 297-311.

Vautard, R., Gill, M., 1989. Singular spectrum analysis in nonlinear dynamics with applications to paleoclimatic time series. Physica D 35, 395-424.

Wallace, J.M., Smith C., Bretherton, C.S., 1992. Singular value decomposition of winter sea surface temperature and $500 \mathrm{mb}$ height anomalies. Journal of Climate 5, 561-576.

Weare, B.C., Nasstrom J.S., 1982. Examples of extended empirical orthogonal function analysis. Monthly Weather Review 110, 481-485.

White, R.M., Cooley, D.S., Derby, R.C., Seaver, F.A., 1958. The Development of Efficient Linear Statistical Operators in the Prediction of Sea-Level Pressure. Journal of Atmospheric Sciences 15, 426-434. 
Table 1

Monthly ranges (min and max) of physico-chemical parameters. (-) Missing measurement

\begin{tabular}{cccccc}
\hline Month & $\begin{array}{c}\mathrm{T} \\
\left({ }^{\circ} \mathrm{C}\right)\end{array}$ & $\mathrm{S}$ & $\begin{array}{c}\mathrm{O}_{2} \\
\left(\mathrm{mg} \mathrm{l}^{-1}\right)\end{array}$ & $\begin{array}{c}\mathrm{SM} \\
\left(\mathrm{mg} \mathrm{l}^{-1}\right)\end{array}$ & $\begin{array}{c}\mathrm{Tr} \\
(\mathrm{m})\end{array}$ \\
\hline Jan & $11.5-11.9$ & $32.0-36.0$ & $6.3-10.0$ & $17.6-38.5$ & $0.9-4.2$ \\
Feb & $13.5-14.5$ & $32.0-36.0$ & - & - & $0.8-2.8$ \\
Mar & $15.5-16.5$ & $33.1-35.9$ & - & $22.3-35.7$ & $1.3-4.6$ \\
Apr & $18.3-19.1$ & $33.6-36.1$ & $5.7-6.2$ & $11.3-20.9$ & $1.5-3.6$ \\
May & $21.8-23.6$ & $33.9-36.2$ & $5.5-9.2$ & $7.0-27.8$ & $1.2-6.0$ \\
Jun & - & - & - & - & - \\
Jul & $26.5-27.7$ & $34.3-36.8$ & $3.1-4.6$ & $8.9-19.3$ & $0.6-4.0$ \\
Aug & $28-29.5$ & $34.5-36.6$ & $4.2-7.3$ & $7.5-37.6$ & $1.2-4.0$ \\
Sep & $26.3-28.4$ & $34.7-36.5$ & - & $7.2-14.0$ & $1.2-3.9$ \\
Oct & - & - & - & - & - \\
Nov & $16.7-17.4$ & $33.0-36.5$ & - & $17.9-29.0$ & $1.4-2.7$ \\
Dec & $14.3-15.3$ & $33.1-36.5$ & - & $17.5-28.7$ & $1.3-2.5$ \\
\hline
\end{tabular}

Table 2

Monthly ranges (min and max) of chemical $\left(\mathrm{NH}_{4}, \mathrm{NO}_{2}, \mathrm{NO}_{3}, \mathrm{PO}_{4}, \mathrm{NT}\right.$ and PT) and biological parameters (Chl a and Pheo). (-) Missing measurement.

\begin{tabular}{|c|c|c|c|c|c|c|c|c|}
\hline Month & $\begin{array}{c}\mathrm{N}-\mathrm{NH}_{4} \\
(\mu \mathrm{M})\end{array}$ & $\begin{array}{c}\mathrm{N}-\mathrm{NO}_{2} \\
(\mu \mathrm{M})\end{array}$ & $\begin{array}{l}\mathrm{N}-\mathrm{NO}_{3} \\
(\mu \mathrm{M})\end{array}$ & $\begin{array}{c}\mathrm{P}-\mathrm{PO}_{4} \\
(\mu \mathrm{M})\end{array}$ & $\begin{array}{l}\text { N-NT } \\
(\mu \mathrm{M})\end{array}$ & $\begin{array}{l}\text { P-PT } \\
(\mu \mathrm{M})\end{array}$ & $\begin{array}{l}\text { Chl a } \\
\left(\mu \mathrm{g} \mathrm{I}^{-1}\right)\end{array}$ & $\begin{array}{l}\text { Pheo } \\
\left(\mu \mathrm{g} \mathrm{I}^{-1}\right)\end{array}$ \\
\hline Jan & - & $0.4-0.5$ & $0.5-2.8$ & $0.1-0.3$ & - & $1.7-2.0$ & - & $0.5-2.9$ \\
\hline Feb & $0.5-1.8$ & - & $1.6-3.8$ & $<0.4$ & - & $1.7-2.0$ & $3.4-4.5$ & - \\
\hline Mar & $0.2-2.3$ & - & - & $0.1-0.4$ & - & - & $2.1-5.3$ & $0.9-4.7$ \\
\hline Apr & $0.5-1.6$ & $0.3-0.7$ & - & - & $\begin{array}{c}12.4- \\
17.4\end{array}$ & $1.6-2.0$ & $4.7-6.2$ & $0.5-4.1$ \\
\hline May & $<2.1$ & $0.1-0.9$ & $0.2-4.3$ & $<0.7$ & $9.0-16.7$ & $0.7-1.6$ & $4.0-6.0$ & $<4.9$ \\
\hline Jun & - & - & - & - & - & - & - & - \\
\hline Jul & $1.4-3.4$ & $0.1-0.7$ & $0.6-2.2$ & $0.1-0.6$ & $10.2-14.6$ & $1.1-1.4$ & $2.4-7.2$ & - \\
\hline Aug & - & $0.1-1.0$ & $0.4-1.2$ & $0.2-0.6$ & $\begin{array}{c}12.6- \\
15.3\end{array}$ & $1.2-1.9$ & $3.1-9.6$ & $0.9-2.8$ \\
\hline Sep & $0.8-3.2$ & $<0.5$ & $0.1-2.6$ & $<0.3$ & $6.5-17.5$ & $1.1-2.3$ & $4.3-6.9$ & $0.1-5.4$ \\
\hline Oct & - & - & - & - & - & - & - & - \\
\hline Nov & - & $<0.9$ & - & $<0.2$ & $8.2-13.9$ & $1.4-2.5$ & $2.4-5.6$ & - \\
\hline Dec & - & - & $1.2-2.9$ & - & - & $0.5-2.8$ & - & - \\
\hline
\end{tabular}


Table 3

Weights of parameters involved in modes 1 and 2 of the permanent features. (-) Not significant weight.

\begin{tabular}{ccc}
\hline Parameters & \multicolumn{2}{c}{ Mean Weight } \\
\cline { 2 - 3 } & Mode 1 & Mode 2 \\
\hline T & -1.20 & $0.20(-)$ \\
S & 1.60 & $0.30(-)$ \\
Tr & 0.70 & 0.70 \\
MES & $-0.09(-)$ & $-0.40(-)$ \\
Tr\% & -1.00 & -0.50 \\
O2 & $0.09(-)$ & $0.06(-)$ \\
NO2 & $0.10(-)$ & $0.20(-)$ \\
NO3 & $-0.10(-)$ & $-0.30(-$ \\
NH4 & $0.08(-)$ & $-0.20(-)$ \\
NT & $-0.26(-)$ & $0.40(-)$ \\
PO4 & $-0.14(-)$ & $-0.02(-)$ \\
PT & $0.04(-)$ & $0.04(-)$ \\
Chla & $0.30(-)$ & -0.80 \\
Pheo & $-0.30(-)$ & 0.80 \\
\hline
\end{tabular}

Table 4

Spatial variance of parameters involved in mode 1 of variable features. (-) Not significant contribution.

\begin{tabular}{cc}
\hline Parameters & Variance \\
\hline T & 0.99 \\
S & 0.90 \\
Tr (-) & 0.50 \\
MES (-) & 0.03 \\
Tr\% (-) & 0.20 \\
O2 & 0.90 \\
NO2 (-) & 0.30 \\
NH4 (-) & 0.70 \\
NO3 & 0.50 \\
NT (-) & 0.50 \\
PO4 & 0.60 \\
PT (-) & 0.40 \\
Chla & 0.60 \\
Pheo (-) & 0.10 \\
\hline
\end{tabular}




\section{Figures}

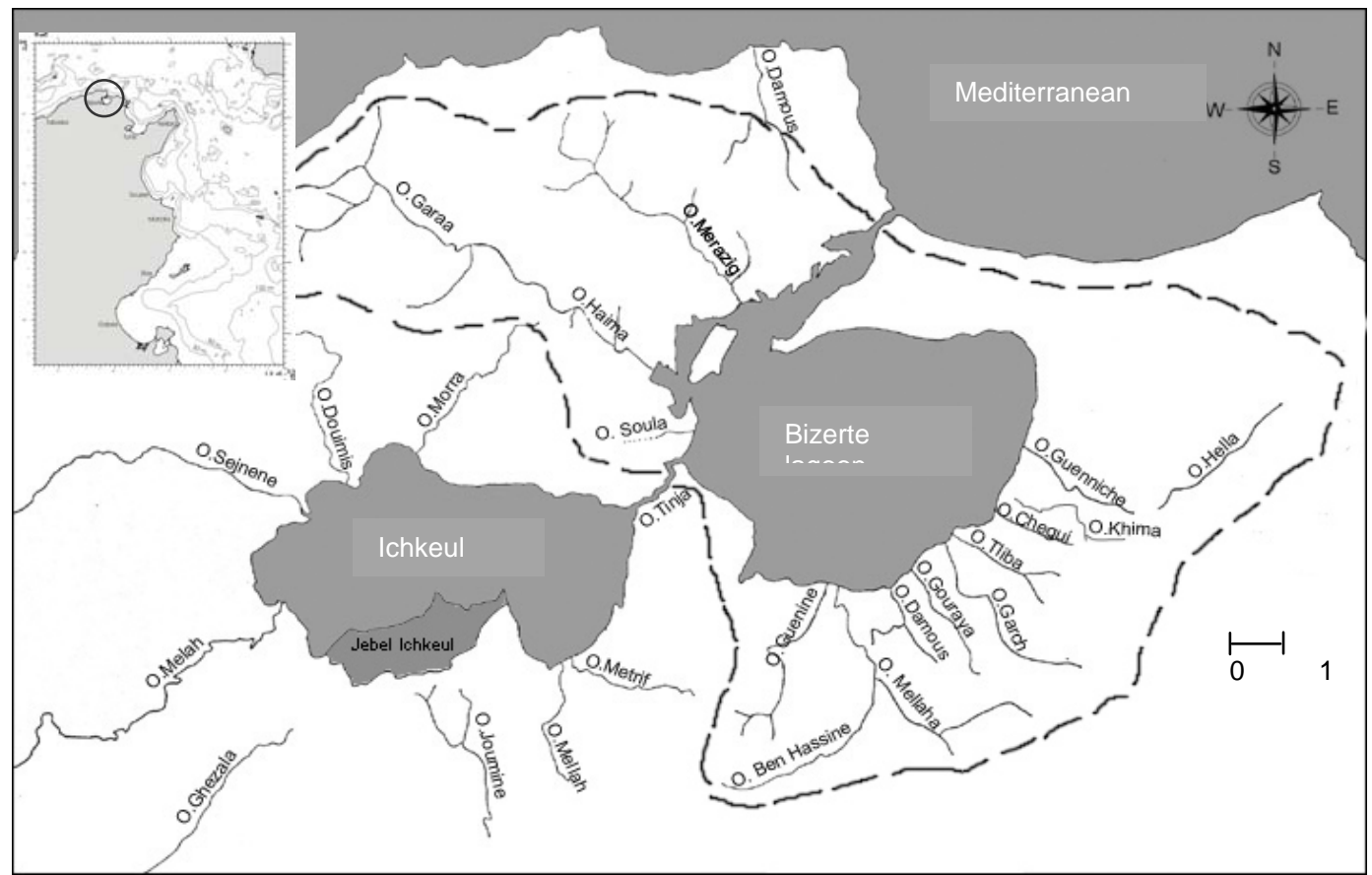

Fig. 1. Geographical location and catchment area of the Bizerte Lagoon. The figure also shows the hydrographic network and the connection of the lagoon with the Ichkeul Lake and the Mediterranean Sea.

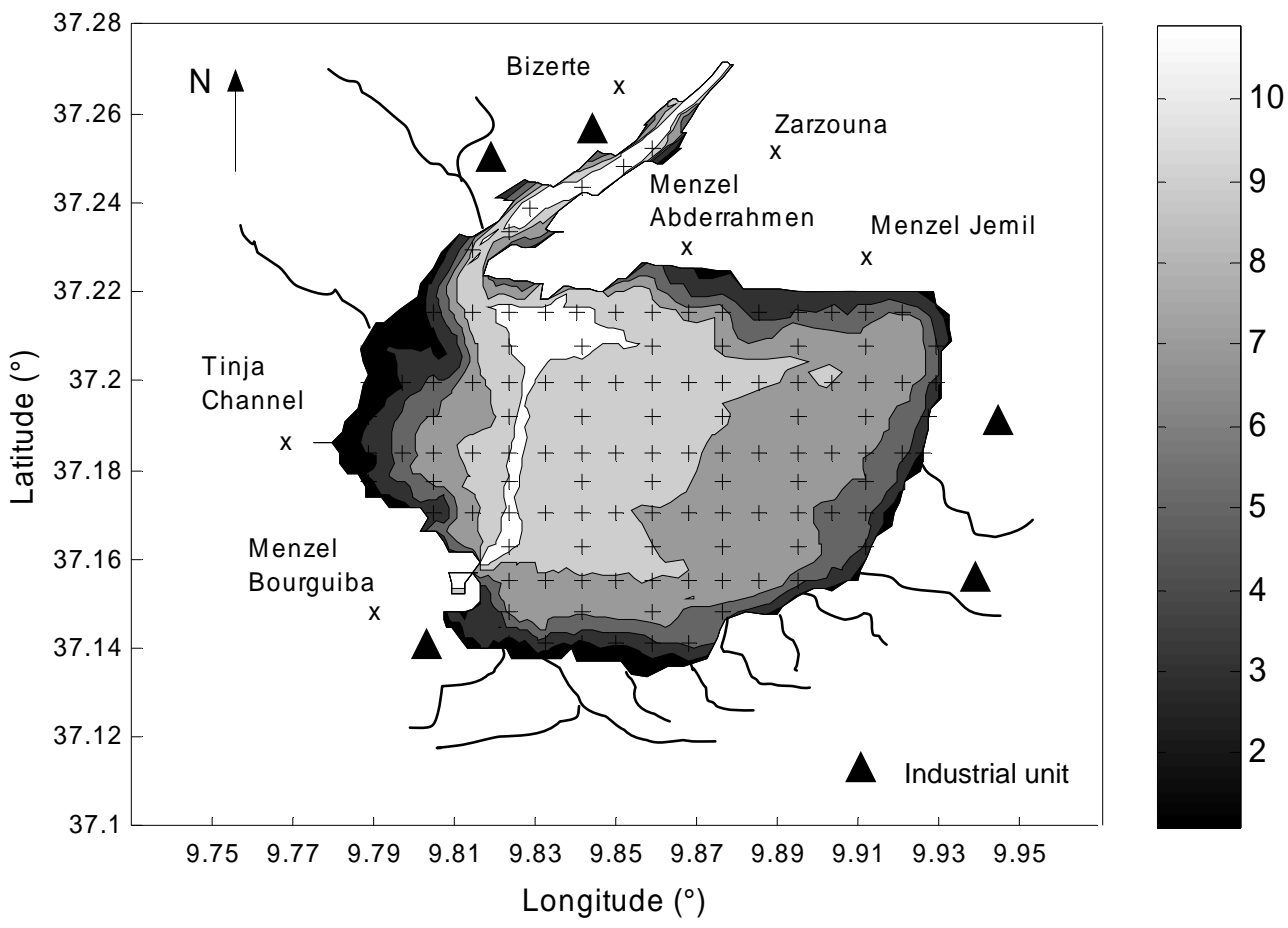

Fig. 2. Bathymetry of the Bizerte lagoon (contour interval $2 \mathrm{~m}$ ) and sampling stations (+). The locations of the main cities are also shown. 


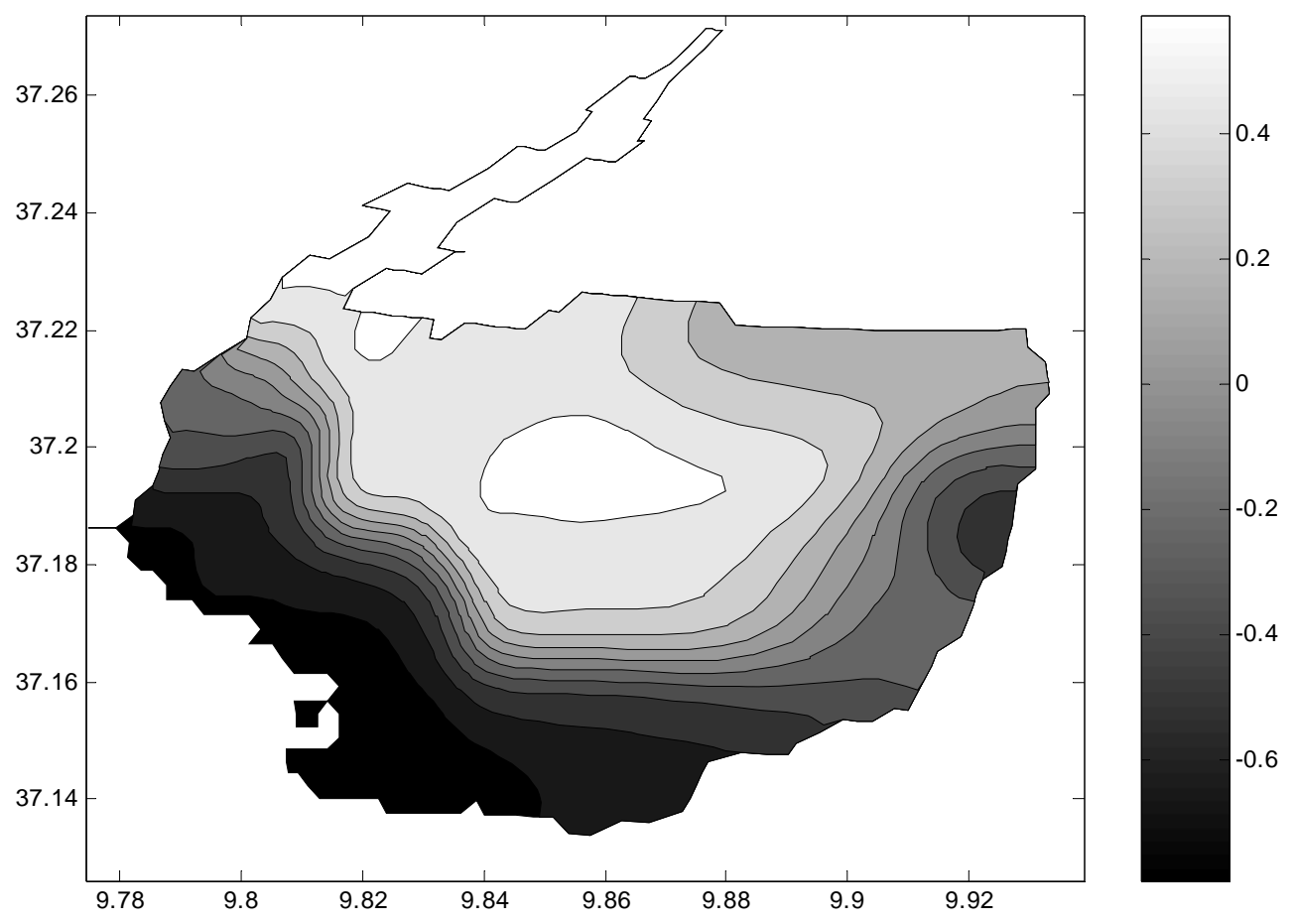

Fig. 3. First mode loadings of the permanent features EOF decomposition. Loadings are normalized.

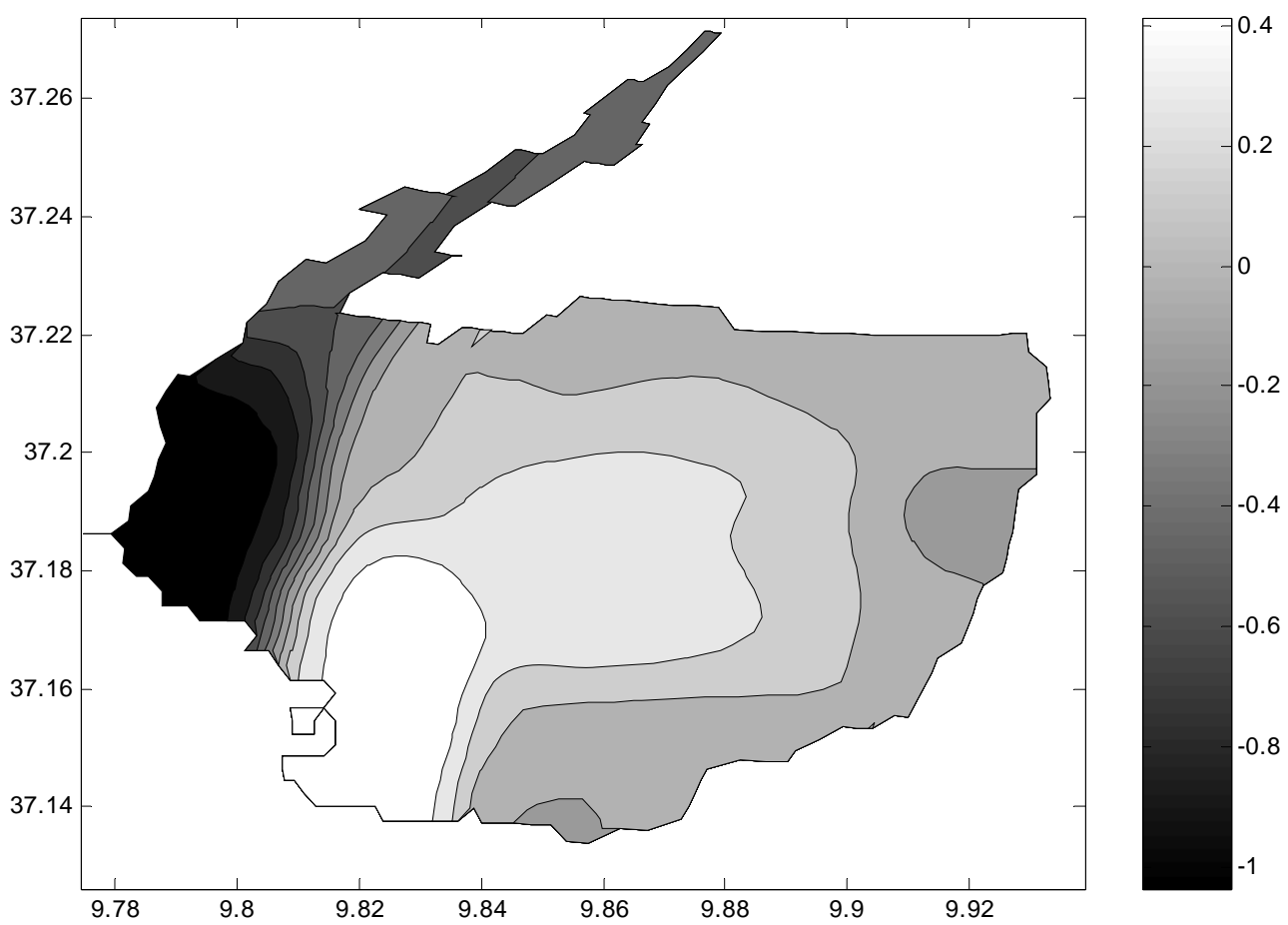

Fig. 4. As Fig. 3 but for the second mode 

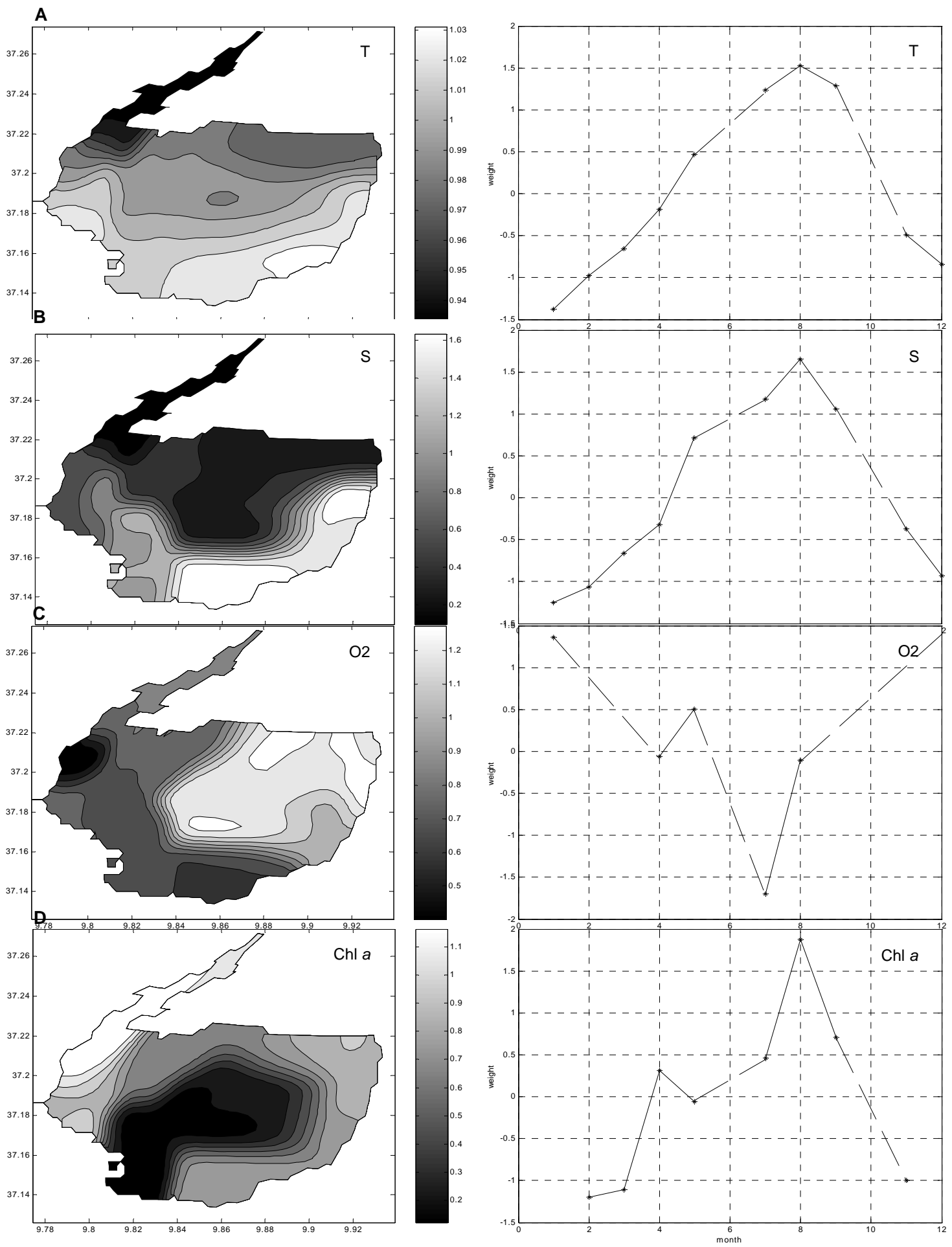

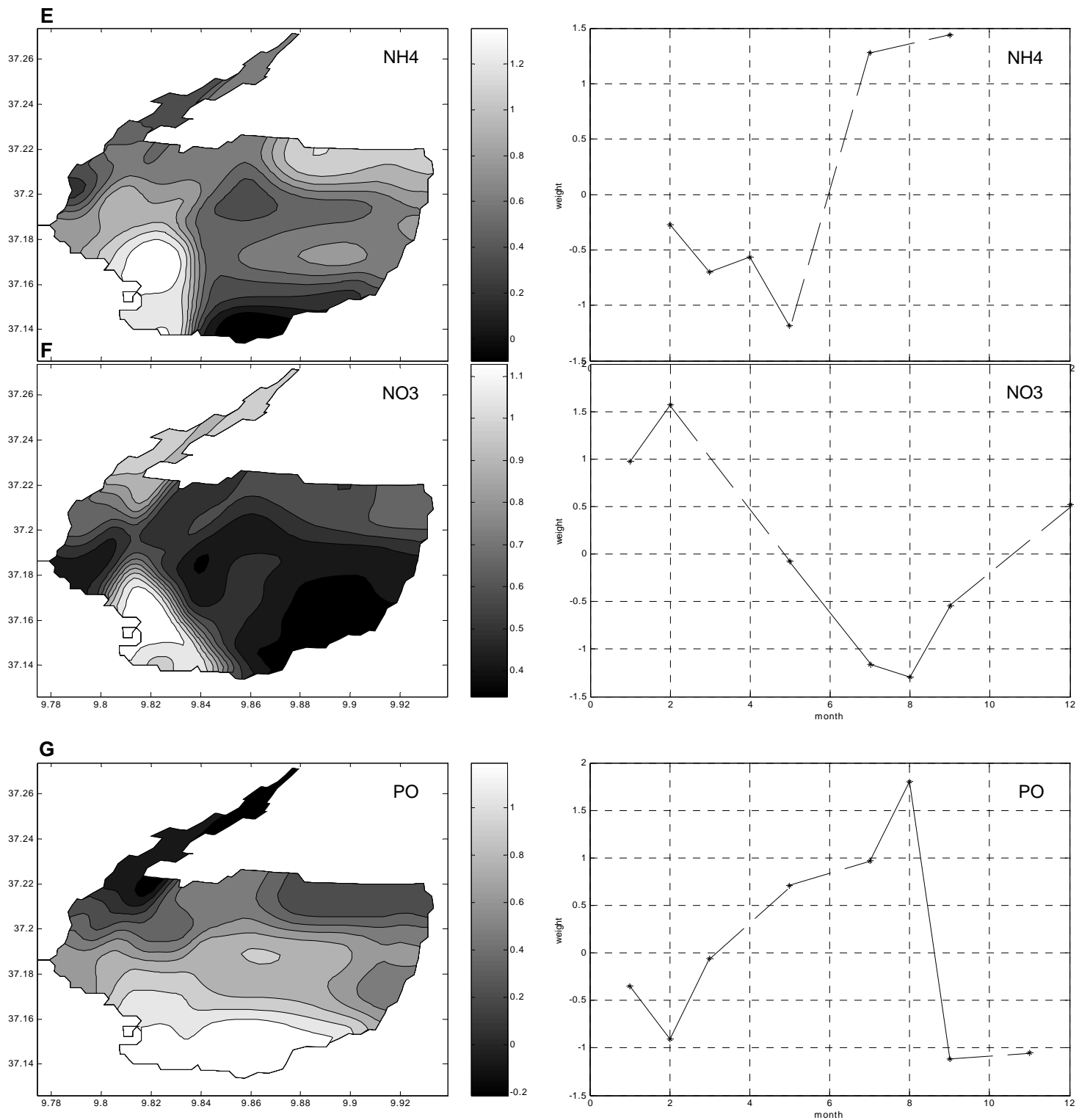

Fig. 5. Loadings (left panel) and weight series (right panel) of the first mode of the variable features EOF decomposition. Loadings and weight series are normalized. Continuous line joins successive observations. Dashed line indicates missing measurements. 